\title{
A Study of Spatially Resolved Temperature Diagnostics for High Explosives
}

H. W. H. Lee

April 5, 2000

U.S. Department of Energy

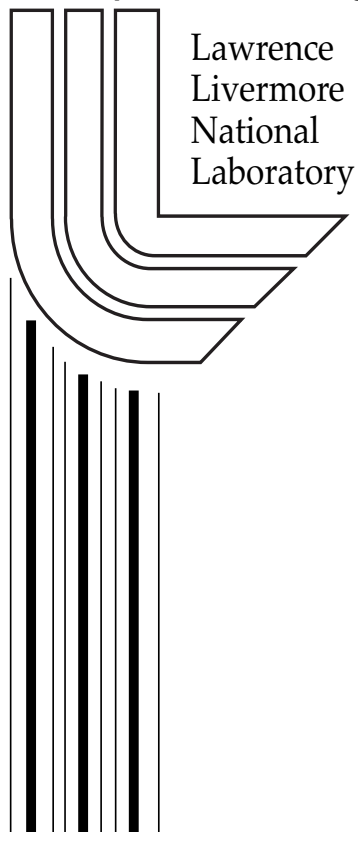




\section{DISCLAIMER}

This document was prepared as an account of work sponsored by an agency of the United States Government. Neither the United States Government nor the University of California nor any of their employees, makes any warranty, express or implied, or assumes any legal liability or responsibility for the accuracy, completeness, or usefulness of any information, apparatus, product, or process disclosed, or represents that its use would not infringe privately owned rights. Reference herein to any specific commercial product, process, or service by trade name, trademark, manufacturer, or otherwise, does not necessarily constitute or imply its endorsement, recommendation, or favoring by the United States Government or the University of California. The views and opinions of authors expressed herein do not necessarily state or reflect those of the United States Government or the University of California, and shall not be used for advertising or product endorsement purposes.

This work was performed under the auspices of the U. S. Department of Energy by the University of California, Lawrence Livermore National Laboratory under Contract No. W-7405-Eng-48.

This report has been reproduced directly from the best available copy.

Available electronically at http://www.doc.gov/bridge

Available for a processing fee to U.S. Department of Energy

And its contractors in paper from

U.S. Department of Energy

Office of Scientific and Technical Information

P.O. Box 62

Oak Ridge, TN 37831-0062

Telephone: (865) 576-8401

Facsimile: (865) 576-5728

E-mail: reports@adonis.osti.gov

Available for the sale to the public from

U.S. Department of Commerce

National Technical Information Service

5285 Port Royal Road

Springfield, VA 22161

Telephone: (800) 553-6847

Facsimile: (703) 605-6900

E-mail: orders@ntis.fedworld.gov

Online ordering: http://www.ntis.gov/ordering.htm

OR

Lawrence Livermore National Laboratory

Technical Information Department's Digital Library

http:/ / www.llnl.gov/tid/Library.html 


\title{
A Study of Spatially Resolved Temperature Diagnostics for High Explosives
}

\author{
99-ERI-017
}

Howard W. H. Lee

\section{Introduction}

The next generation of 2-D and 3-D weapon-simulation codes will require marked advances in the spatial and temporal resolution of the various diagnostics to verify the complex physics predicted from these calculations. This is particularly true for the complicated physics of highexplosive (HE) detonation and burn, of which a detailed understanding is crucial to nuclearweapons performance and integrity.

The processes involved in the detonation of HEs occur very rapidly and lead to extremely high pressures (several GPa) and temperatures (several thousand Kelvin). A key diagnostic that has so far eluded experimentalists is a temperature diagnostic for burning HE. Temperature is a basic thermodynamic property that enables a fundamental understanding of important HE physics such as the chemical processes involved in the shock-to-detonation transition, and to assess the thermal part of the equation-of-state of the detonation products. Accurate, spatially localized temperature measurements with high temporal resolution are thus crucial, but are unfortunately lacking. Our work address this important problem.

\section{Accomplishments for FY99 (Half Year)}

This project was funded at the $\$ 50 \mathrm{~K}$ level and for only half a year. For this level of support, we demonstrated several important physics principles that support a new spatially resolved temperature diagnostic for HE burns and shock fronts. Our diagnostic provides (1) a 2-D spatial resolution of 10- to 100- $\mu \mathrm{m}$ (the critical length scale needed for useful modeling of HE burns), (2) single-shot measurement capability, and (3) temporal resolution.

Temperature is determined through the population distribution between two appropriately spaced atomic energy levels $\left(\Delta E=E_{2}-E_{1}\right)$ as indicated in Figure 1. Temperature
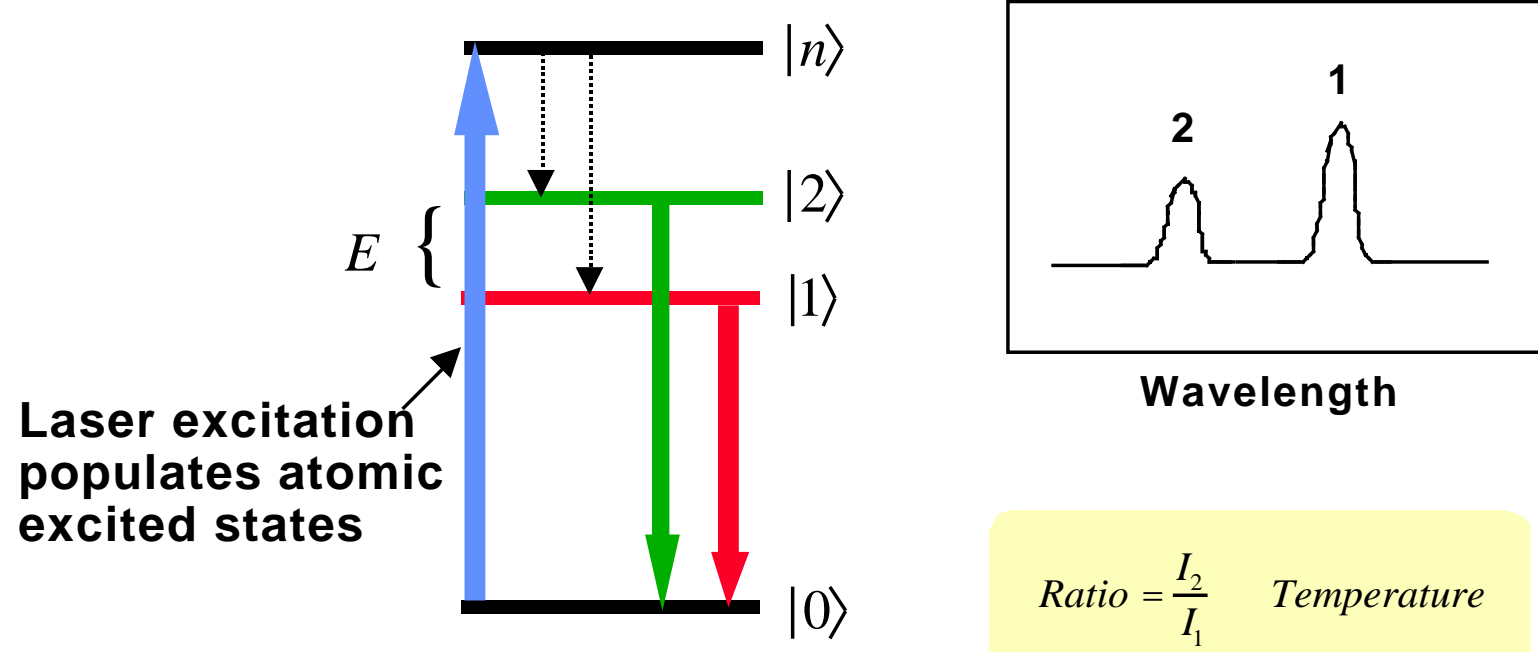

Work was performed under the auspices of the U.S. Department of Energy by University of California Lawrence Livermore National Laboratory under contract No. W-7405-Eng-48. 
Figure 1. Energy level diagram illustrating the operation of temperature diagnostic

is deduced from the population distribution (e.g., Boltzmann), which can be determined with a variety of techniques including luminescent and holographic methods. The population distribution is related to the ratio of the luminescence intensity from the two energy levels, which gives the temperature.

Two requirements for the energy levels are: (1) the energy difference between the levels must approximate the average thermal energy $\left(\Delta E / k_{B} \approx\right.$ expected average temperature); and (2) to mitigate background interference (e.g., blackbody radiation), luminescence should occur in the blue or ultraviolet. Requirement (2) will allow background emission subtraction to minimize interference.

On the basis of these requirements, we studied several atomic systems and succeeded in identifying two rare-earth ions $\left(\mathrm{Tm}^{3+}\right.$ and $\left.\mathrm{Tb}^{3+}\right)$ as promising candidates for the atomic system. Our results indicate that with these ions: (1) the difference in energy levels will allow temperature measurements of a few thousand Kelvin, (2) interference from Doppler and collisional broadening are not limiting problems, and (3) the required number density of atoms for useful signal levels is reasonable.

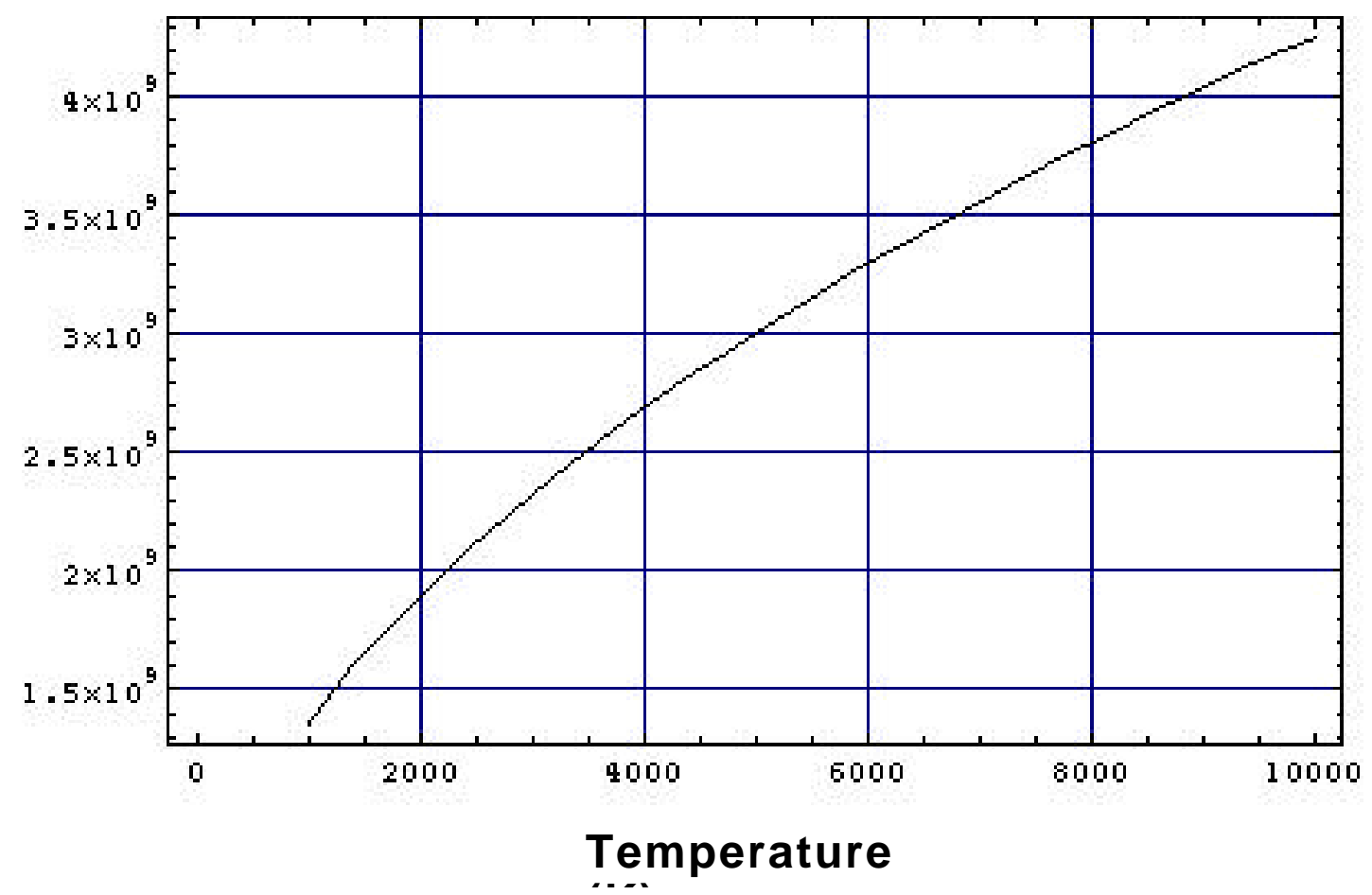

Figure 2. Doppler-broadened linewidth (FWHM) as a function of temperature for $\mathrm{Tb}^{3+}$ ions

Doppler broadening presents a potential problem for this technique, particularly at high temperatures where large linewidths may result. Figure 2 shows a calculation of the Dopplerbroadened linewidth as a function of temperature for $\mathrm{Tb}^{3+}$ ions. This Doppler linewidth is given by

$$
\Delta v_{D}=\frac{\sqrt{8 \ln 2}}{\lambda}\left(\frac{k_{B} T}{M}\right)^{1 / 2}
$$


The results in Fig. 2 show that the Doppler contribution to the overall linewidth is negligible, reaching only a few $\mathrm{GHz}$ at 10,000 K. Therefore, Doppler broadening is not a problem.

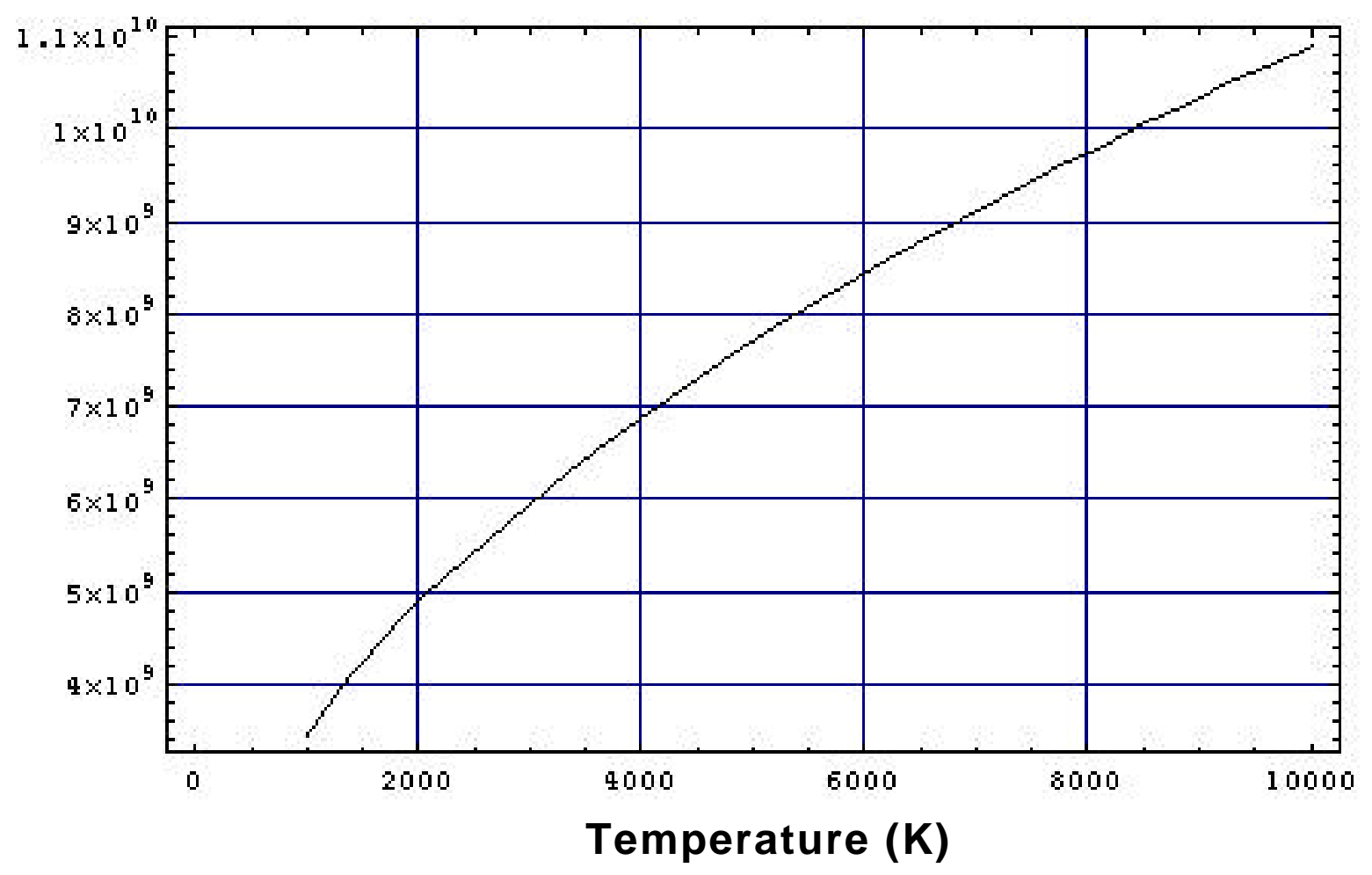

Figure 3. Collisionally-broadened linewidth (FWHM) as a function of temperature for $\mathrm{Tb}^{3+}$ ions.

Collisional processes may also broadened the linewidth of the atomic emission. Figure 3 shows the contribution of collisional broadening to the overall linewidth. This process results in a linewidth $\left(\Delta v_{C}\right)$ given by

$$
\Delta v_{C}=\frac{2 V_{P}}{l_{m f p}} \quad \text { where } \quad V_{p}=\sqrt{\frac{2 k_{B} T}{M}} \quad l_{m f p}=\frac{1}{\pi \sqrt{2} N d^{2}}
$$

Even at elevated temperatures, Fig. 3 shows that collisions result in only a few GHz linewidth. Clearly, collisional broadening does not present a problem to this technique.

We also find that interference from background emission, which may be significant, can be mitigated by increasing number density of atoms (This is in addition to using atomic systems where the luminescence peaks are in the blue or ultraviolet). To see this, we assume a background emission density $(\rho(v))$ given by black body radiation: 


$$
\rho(v)=\frac{8 \pi h v^{3}}{c^{3}} \frac{1}{\exp \left(h v / k_{B} T\right)-1}
$$

If we take luminescence linewidth of rare earth ions to be $\Delta v$ and centered atv, then the contribution from black body radiation is given by integrating the above equation

$$
\int_{v 1}^{v 2} \rho(v) d v=\int_{v 1}^{v 2} \frac{8 \pi h v^{3}}{c^{3}} \frac{1}{\exp \left(h v / k_{B} T\right)-1} d v
$$

The density of rare earth ions needed to give an luminescence energy density comparable to the background radiation is then given by

$$
\rho_{\text {atoms }}(v, \Delta v, T)=\frac{1}{\eta h v} \int_{v 1}^{v 2} \rho(v) d v
$$

where $\eta$ is the quantum efficiency of the atomic emission. The results are given in Fig. 4

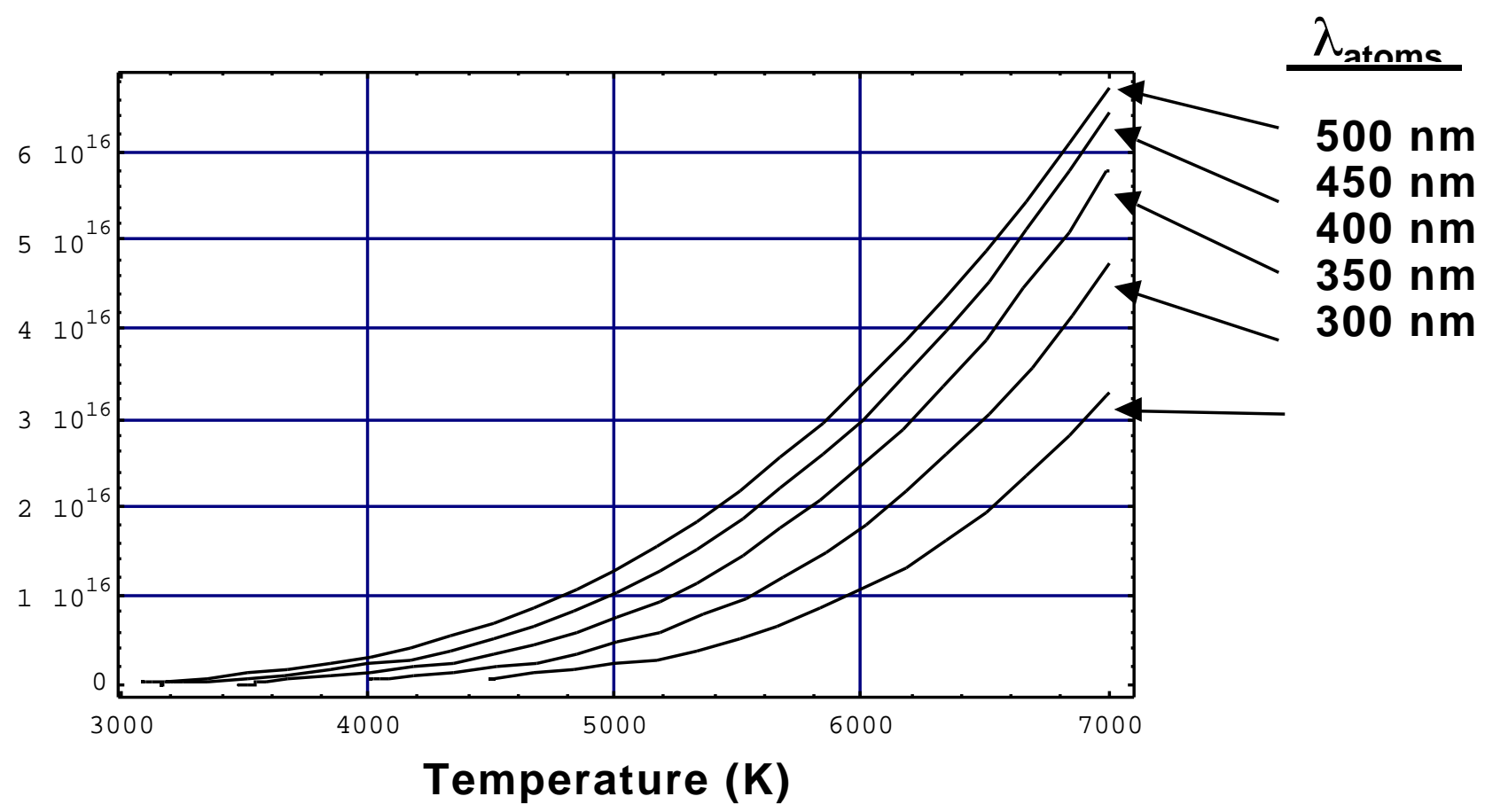

Figure 4. Number density $\left(\mathrm{cm}^{-3}\right)$ of atomic systems required to give luminescence comparable to black body radiation. This is plotted as a function of temperature.

The required density is inversely proportional to $\eta$. Typical $\eta$ 's for optical transitions of interest (high energy) are $\sim 50 \%$. If we assume $\eta=100 \%$ and $\Delta v$ (FWHM) $\sim 10 \mathrm{~nm}$, then the required 
number densities are all in the $10^{16} \mathrm{~cm}^{-3}$ range, which is reasonable. This shows that the luminescence from the atomic system can be observed above the background emission, which is an important result.

Finally, we designed and began construction of an experimental system to implement our temperature diagnostic (shown in Fig. 5). In this design, (1) the luminescence is collected either with free-space optics or with a 2-D imaging fiber, (2) the design of the collection optics determines the area and spatial resolution of the measurement, and (3) an excitation laser initially populates the excited states and enters through the collection optics. Then, (1) a fraction of the collected light from the HE burn is directed to a 2-D detector array (Detector 0 ), which provides a background emission spectrum to allow its subtraction and thus minimizes its interference with the atomic luminescence, and (2) the remainder of the luminescence is directed to two other 2-D detector arrays (Detectors 1 and 2) where optical filters separate the spatial image of the luminescence from each atomic level. Information from all three detector arrays is computerprocessed into a 2-D temperature image, which, with proper design of the imaging optics, permit a spatial resolution of 10 to $100 \mu \mathrm{m}$. With 2-D detector arrays such as what we have designed, single-shot information is possible, along with time-resolved 2-D temperatures. This represents critical capabilities that presently do not exist.

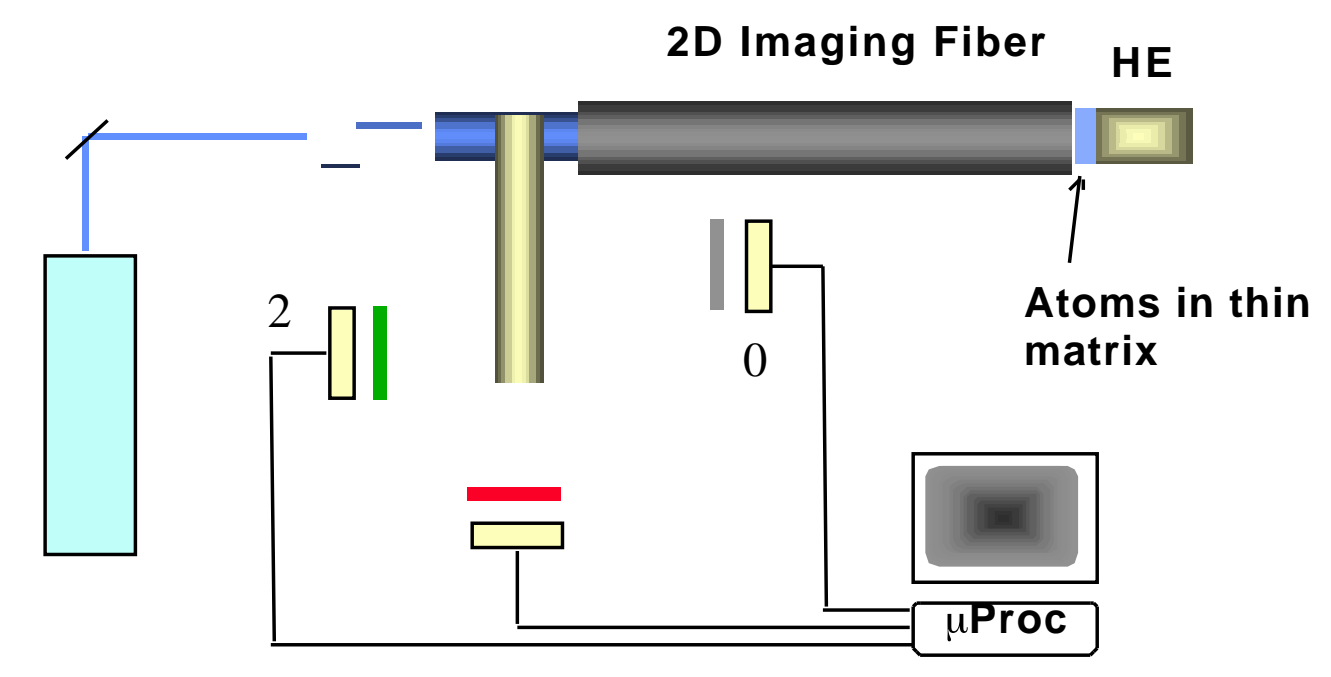

Figure 5. Implementation of spatially and temporally resolved temperature diagnostic for HEs 